\title{
SOBRE EL PINTOR SEVILLANO FRANCISCO PÉREZ DE PINEDA: UNA APORTACIÓN INÉDITA A SU CATÁLOGO
}

\author{
José RodA PEÑA ${ }^{1}$ \\ Universidad de Sevilla
}

\begin{abstract}
Se documenta un nuevo lienzo del pintor sevillano Francisco Pérez de Pineda (1641-1724): El Niño Jesús y San Juanito con el cordero, realizado en 1693 para la desaparecida parroquia de San Miguel, conservado hoy por la Hermandad del Silencio en sus dependencias de la iglesia de San Antonio Abad, en Sevilla.

Palabras clave: Francisco Pérez de Pineda; pintura barroca sevillana; siglo XVII; parroquia de San Miguel; iglesia de San Antonio Abad; Hermandad del Silencio.
\end{abstract}

\section{ABOUT THE SEVILLIAN PAINTER FRANCISCO PÉREZ DE PINEDA: AN UNPUBLISHED CONTRIBUTION TO HIS CATALOGUE}

\begin{abstract}
The author documents a new oil on canvas of Sevillian painter Francisco Pérez de Pineda (1641-1724): Christ child and the infant Saint John with the lamb, made in 1693 for the disappeared parish of Saint Michael, today preserved by the Brotherhood of Silence, in its dependencies of the church of Saint Anthony the Abbot, at Seville.

Key words: Francisco Pérez de Pineda; baroque Sevillian painting; $17^{\text {th }}$ century; Saint Michael parish; Saint Anthony the Abbot church; Brotherhood of Silence.
\end{abstract}

Cómo citar este artículo / Citation: Roda Peña, José (2020): "Sobre el pintor sevillano Francisco Pérez de Pineda: una aportación inédita a su catálogo". En: Archivo Español de Arte, vol. 93, núm. 369, Madrid, pp. 73-80. https://doi.org/10.3989/aearte.2020.06.

Procedentes de la extinta parroquia sevillana de San Miguel, tristemente demolida por acuerdo de la junta revolucionaria de 1868, se trasladaron al Museo de Bellas Artes una serie de pinturas consideradas "de mérito", algunas de las cuales terminarían por depositarse, al poco tiempo, en la cercana iglesia de San Antonio Abad, donde permanecen. Entre las mismas se encuentra un óleo sobre lienzo de formato horizontal donde se representa al Niño Jesús y San Juanito con el cordero $(105 \times 160 \mathrm{~cm})$, que al tiempo de su transferencia al Museo se encontraba "en regular estado" y se consideraba "copia de Murillo"2.

Comenzaremos evocando que en la vetusta fábrica gótica de San Miguel, su capilla bautismal estaba situada en la nave de la epístola ${ }^{3}$. Para este recinto, Luis Nieto, un casi ignoto pintor de

1 roda@us.es / ORCID iD: http://orcid.org/0000-0002-4141-1178.

2 Tassara, 1919: 74. El autor transcribe un inventario de las pinturas de la derruida parroquia de San Miguel que fueron llevadas al Museo, cuyo documento consultó en el Archivo de la Real Academia de Bellas Artes de Santa Isabel de Hungría de Sevilla.

3 González de León, 1844: 35-36. Tras la parcial renovación neoclásica del templo — particularmente visible en el caso de sus retablos_- impulsada por su párroco Francisco de Paula Vega en 1827, la pila de cristianar se mudó a los pies de la nave del evangelio. 
imaginería ${ }^{4}$, recibía del mayordomo de fábrica la suma de 60 reales por "pintar y estofar [...] en la pared de ella el Baptismo de Señor San Juan en virtud de mandato del Arzobispo mi Señor", firmando el correspondiente recibo el 24 de mayo de $1687^{5}$. Pasado poco más de un lustro, el baptisterio parroquial, amén de la anterior composición pictórica mural, se enriqueció con la presencia de dos "quadros de pintura, el uno del Baptismo de San Juan y el otro de Jesús y San Juan con el Cordero, con molduras de madera y dorados", por los cuales le fueron abonados al maestro pintor Francisco Pérez de Pineda 302 reales y cinco maravedíes, como consta del justificante de pago que firmara el 28 de septiembre de $1693^{6}$. Del lienzo del Bautismo de Cristo se desconoce su paradero, pues ni siquiera aparece registrado en el inventario de las pinturas que se condujeron al Museo tras la clausura y derribo de la parroquia de San Miguel, a finales de 18687. En cambio, la de "Jesús y San Juan con el Cordero" sí que recorrió ese periplo ${ }^{8}$ hasta llegar a la iglesia de San Antonio Abad, conservándose hoy en el despacho del hermano mayor de la Hermandad del Silencio, cofradía de penitencia que tiene establecida su sede canónica en el referido templo [fig. 1].

La pintura que es objeto de nuestro estudio pasó desapercibida para la historiografía artística hasta que en 1981 fue dada a conocer por Diego Angulo, quien acertadamente la relacionó con "un discípulo o continuador de Murillo de cierta calidad", señalando su inspiración en un cuadro de Rubens, así como la aparente correspondencia de su estilo con el que refleja el medio punto de Santo Domingo confesando con Cristo que, procedente del convento de San Pablo de Sevilla - actual parroquia de Santa María Magdalena-, se halla en el Museo de Bellas Artes hispalense ${ }^{9}$, cuya factura terminó por atribuir Enrique Valdivieso a los pinceles de Andrés Pérez ${ }^{10}$. Este último, precisamente, es hijo del autor del lienzo que analizamos, que el propio Valdivieso ha venido asignando durante los últimos años a Juan Simón Gutiérrez (1634-1718)11, aunque la documentación parroquial de San Miguel nos ha desvelado su verdadera paternidad artística, debida a Francisco Pérez de Pineda en 1693.

Las primeras noticias sobre Francisco Pérez de Pineda (1641-1724) las proporcionó Ceán Bermúdez, afirmando ser "natural de Sevilla y discípulo de Murillo, a quien procuró imitar". De igual modo, pudo constatar la presencia de su nombre entre los concurrentes de la academia de pintura de la Casa Lonja entre 1664 y 1673, así como que fue padre de dos vástagos que ejercieron como pintores: Andrés (1660-1727), de quien ya hemos hecho referencia y que fue un hijo natural, y Francisco (1686-1732), fruto de su segundo matrimonio con Leonarda Jacinta Romero ${ }^{12}$ [fig. 2]. Estos pocos datos se vieron ampliados progresivamente, desde bien entrado el siglo XX, con las aportaciones de varios historiadores del arte, a las que también podemos sumar ahora algunas sustanciales notas inéditas. En apretado resumen, recordaremos que Francisco Pérez de Pineda fue hijo del matrimonio formado por Andrés Pérez de Híjar y Mariana de Pineda, siendo bautizado en la

${ }^{4}$ Kinkead, 2007: 390-391. Hernández, 2009: 57-59. García, 2014: 269. Figura entre 1671 y 1674 como uno de los asistentes a la academia de pintura de la ciudad. Residió sucesivamente en Triana y en las collaciones de San Martín y San Salvador. En 1679, junto a su colega Domingo Mejía, dieron carta de pago por el dorado y estofado de una escultura de San Francisco de Asís tallada por Francisco Antonio Gijón para la villa extremeña de Zafra.

5 Archivo de la Parroquia de Santa María Magdalena de Sevilla (APSMMS), Sección Parroquia de San Miguel, Libro de Cuentas 1684-1689, f. 270.

${ }^{6}$ APSMMS, Sección Parroquia de San Miguel, Libro de Cuentas 1689-1693, f. 148. "Ytt. se avonan al dicho Mayordomo trescientos y dos reales y cinco maravedíes por los mismos que lo tubieron de costas dos quadros de pintura, el uno del Baptismo de San Juan y el otro de Jesús y San Juan con el Cordero, con molduras de madera y dorados, que están puestos dentro de la Capilla de el Baptismo desta Yglessia, consta de recivo suelto firmado de Francisco Pérez de Pineda, maestro pintor, su fecha en 28 de septiembre de 1693, que se rubricó, 10.273 [maravedíes]".

7 Tassara, 1919: 74.

8 Por un inventario redactado en febrero de 1834 sabemos que este lienzo de "Un San Juan Bautista apaisado con un Niño Dios, como de dos varas y una de alto con sus molduras doradas", permanecía en el muro del lado de la epístola de la parroquia de San Miguel. Pastor, 2018: 113.

9 Angulo, 1981: 200. Estas mismas consideraciones las repite García de la Concha, 1987: 151.

10 Valdivieso, 2003: 490-492. Sobre Andrés Pérez véanse los últimos balances que sobre su biografía y trayectoria artística ofrecen Quiles/Cano, 2006: 106-108; Sánchez, 2008: 63-68; Valdivieso, 2018: 221-243.

11 Valdivieso, 2003: 405; 2018: 146-147. En cambio, lo reproducen como obra anónima del siglo XVIII Quiles/ Cano, 2006: 100 .

12 Ceán, 1800: 80. 


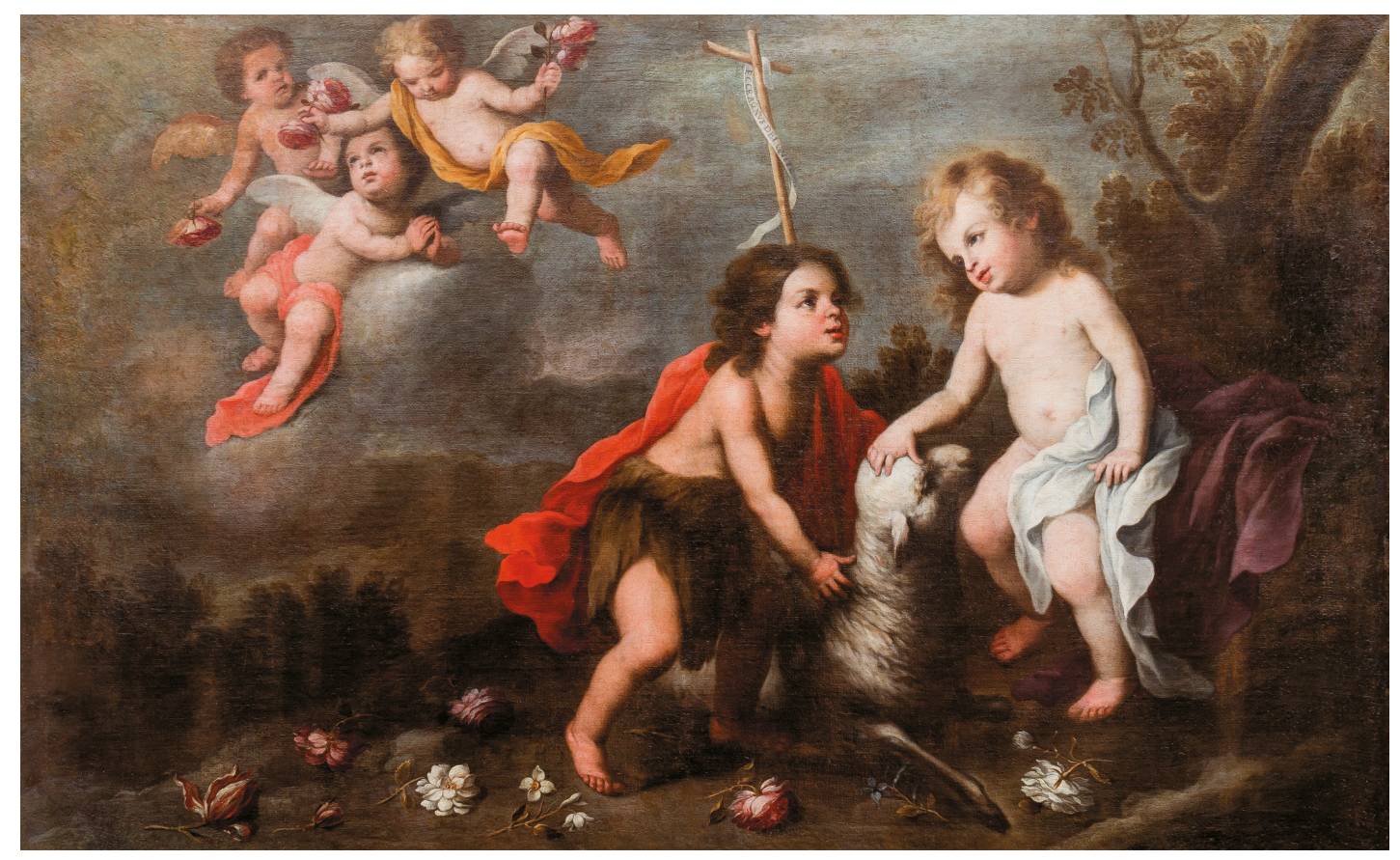

Fig. 1. Francisco Pérez de Pineda. Niño Jesús y San Juanito con el cordero. 1693. Hermandad del Silencio, Sevilla. Foto: Jesús Romero Rodríguez.

Fig. 2. Firma de Francisco Pérez de Pineda en 1675. Foto: José Roda Peña.

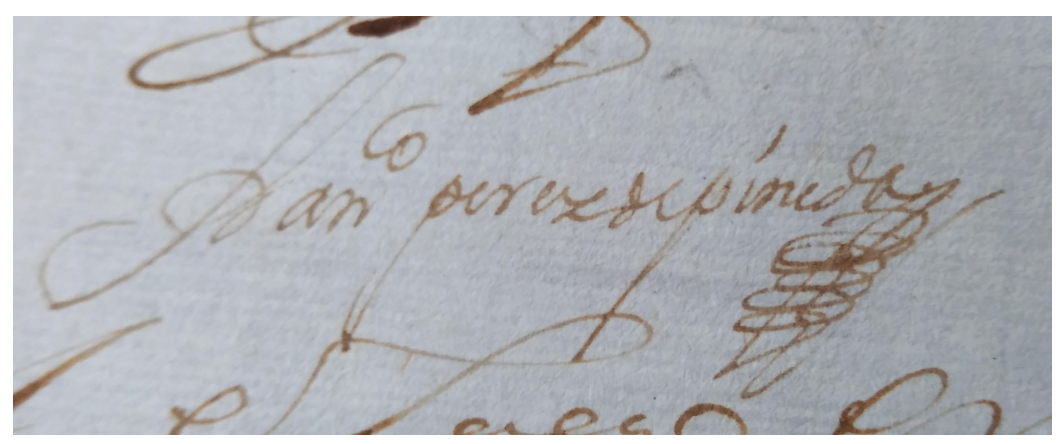

parroquia sevillana de San Vicente el 23 de agosto de $1641^{13}$. Con doce años, el 11 de febrero de 1654, entró como aprendiz de pintor en el taller de Sebastián de Llanos y Valdés (c. 1605-1677) ${ }^{14}$. En 1667 se casó con Ana Ventura de Escalera Tinajero ${ }^{15}$ y, tras enviudar en 1674, contrajo nuevas nupcias en 1675 con la aludida Leonarda Jacinta Romero $(\dagger 1709)^{16}$. Cerca de dos años los pasó en

13 Cañizares, 2019: 90.

14 Kinkead, 1979: 193 y 199.

15 Kinkead, 2007: 443.

16 Expediente matrimonial de Francisco Pérez de Pineda con Leonarda Jacinta Romero, 1675, Archivo General del Arzobispado de Sevilla (AGAS), fondo Arzobispal, sección Vicaría, serie expedientes matrimoniales ordinarios, caja 1446. En su expediente matrimonial, incoado el 11 de enero de 1675, Francisco Pérez de Pineda nos revela que, después de haber enviudado hacía unos tres meses, se trasladó a vivir a la collación de San Lorenzo desde la del Salvador, donde tenía su anterior residencia. La futura contrayente, Leonarda Jacinta Romero, afirma tener 19 años, siendo parroquiana de Omnium Sanctorum, donde se produjo el casamiento. Algunas otras noticias biográficas de Francisco 


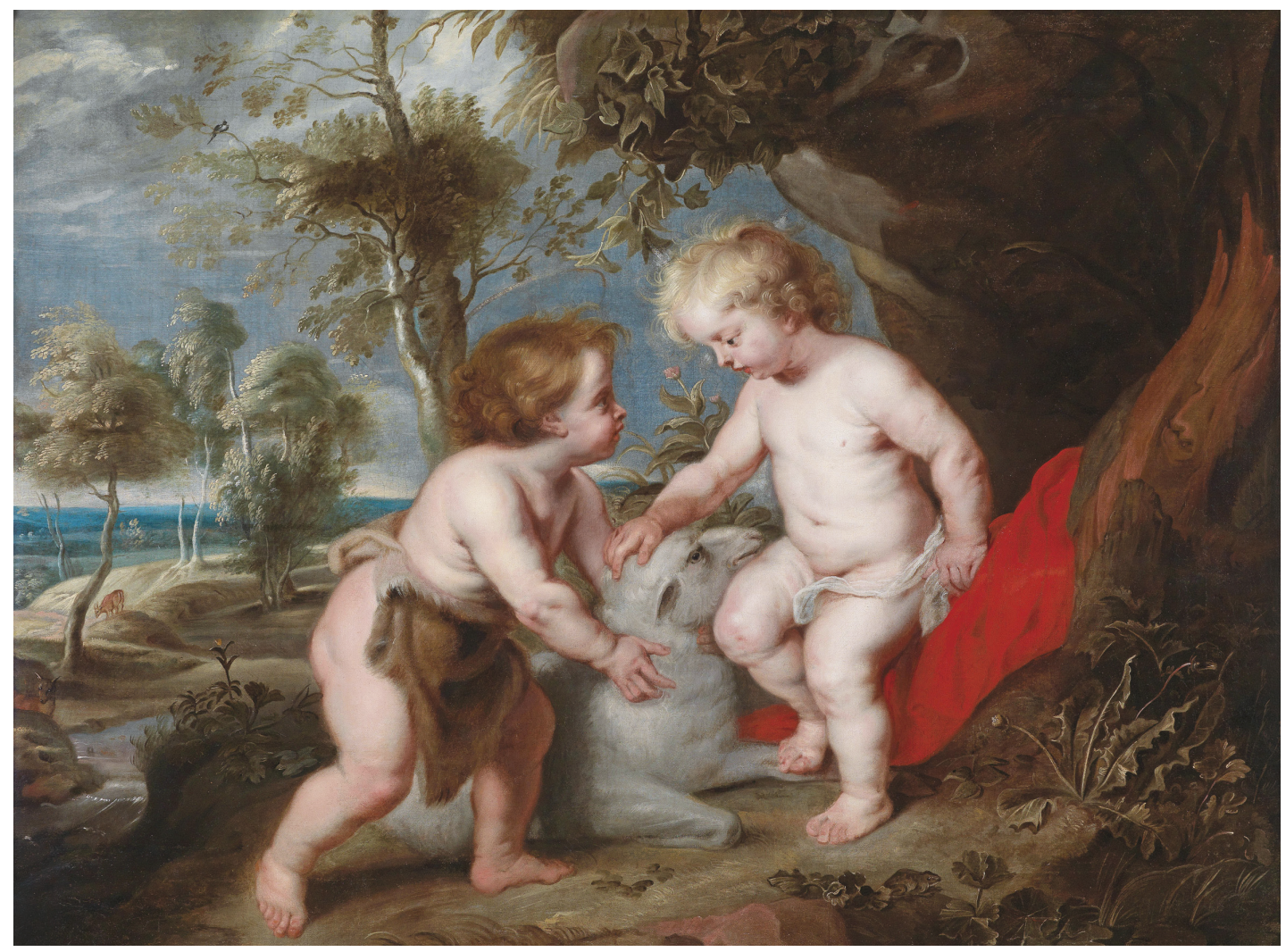

Fig. 3. Pedro Pablo Rubens y taller. Niño Jesús y San Juanito en un paisaje. c. 1630. Foto: C Dorotheum, Viena.

México, entre 1680 y $1682^{17}$. Digna de reseñarse es su vinculación con la parroquia sevillana de San Lorenzo, en cuya feligresía residió durante buena parte de su existencia, siendo recibido como cofrade de sus hermandades sacramental y de las ánimas benditas del purgatorio, en cuyos órganos de gobierno ejerció cargos de responsabilidad ${ }^{18}$. Con el párroco de San Lorenzo, Diego Rodríguez de Orihuela, contrató en 1686 la factura de los dos grandes lienzos que habrían de decorar los paramentos laterales del presbiterio ${ }^{19}$, un Triunfo de la Cruz y el Triunfo de la Eucaristía, del que solo se conserva in situ el segundo de ellos, por cierto en un pésimo estado de conservación. Pasaron varios lustros, hasta que en 1707 Francisco Pérez de Pineda dio inicio a las pinturas murales de la capilla sacramental de esta misma iglesia, una tarea que se paralizó por falta de fondos de la cofradía eucarística, y que cuando pudo reanudarse una década más tarde, al no llegarse a un acuerdo económico con el artífice, terminó por concertarse con Domingo Martínez y Gregorio de Espinal, quienes la concluyeron en $1718^{20}$. La muerte le alcanzó a los 83 años de edad, teniendo lugar su entierro en la parroquia de San Lorenzo el 22 de septiembre de $1724^{21}$.

Pérez de Pineda y de su entorno familiar las suministran Quiles, 1990: 183-187; Quiles/Cano, 2006: 118-119 y Kinkead, 2007: 443-450.

17 Quiles/Cano, 2006: 119.

18 En la Sacramental fue diputado (1700-1701/1715-1717) y diputado de arcas (1717-1718), mientras que en la de Ánimas llegaría a ser secretario (1686), mayordomo (1696-1697), diputado (1716-1717) y diputado de cuentas (17171718). Debo estas referencias a la gentileza de D. Ramón Cañizares Japón, archivero de Hermandad Sacramental de la Soledad de San Lorenzo.

19 Quiles/Cano, 2006: 118.

20 Sancho, 1934: 114-115. Morales, 1981: 58-59. Delgado, 2010: 139-142.

21 Cañizares, 2019: 90. 


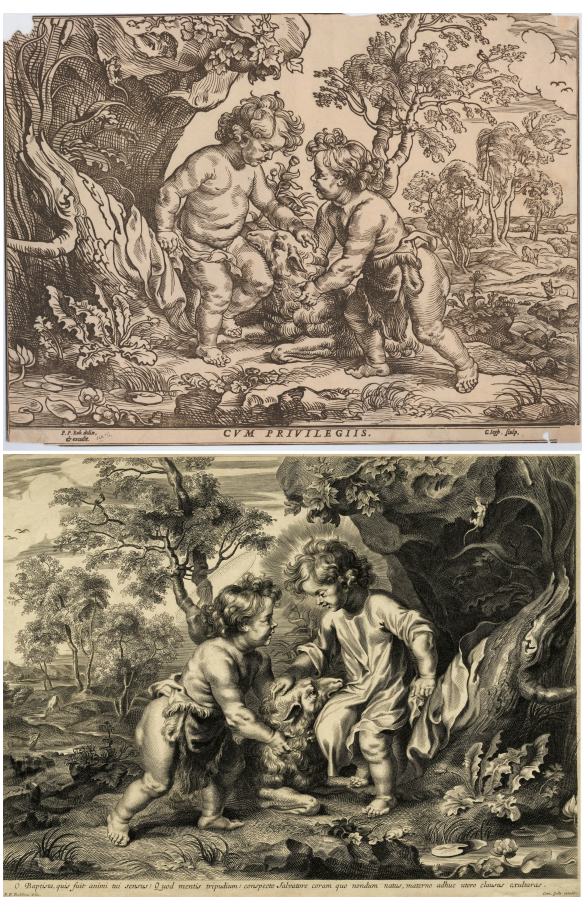

Fig. 4. Grabados de Christoffel Jegher, c. 1632-1636 (arriba) y Cornelis Galle I, c. 1630-1650 (abajo), sobre composición de Pedro Pablo Rubens. Niño Jesús y San Juanito jugando con el cordero. Fotos: (C) The Trustees of the British Museum.

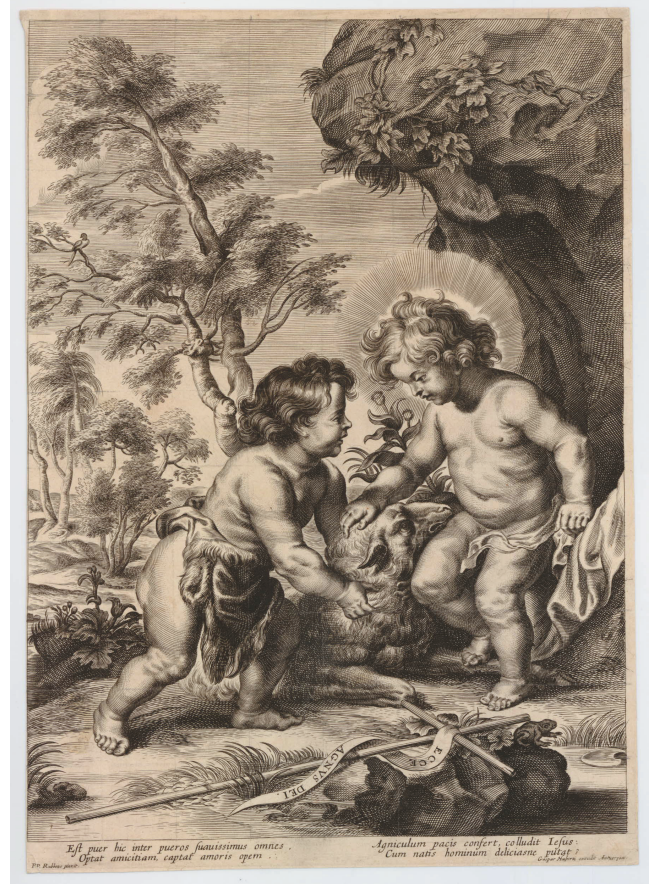

Fig. 5. Grabado de Gaspar Huberti sobre composición de Pedro Pablo Rubens. Niño Jesús y San Juanito jugando con el cordero. Tercer cuarto del siglo XVII. Foto: (C) The Trustees of the British Museum.

Nos interesa poner de manifiesto que el mencionado cuadro del Triunfo de la Eucaristía realizado por Pérez de Pineda en 1686 para la parroquial de San Lorenzo replica el conocido cartón para tapiz diseñado en 1628 por Rubens, con destino al monasterio de las Descalzas Reales de Madrid ${ }^{22}$. Y es que en su obra pictórica debieron de ser frecuentes las citas rubenianas, como sucedió realmente con un significativo elenco de pinturas sevillanas del último tercio del siglo XVII y viene a corroborarlo este segundo óleo que viene a engrosar su producción documentada: el Niño Jesús y San Juanito con el cordero ejecutado en 1693, donde el grupo principal infantil que acaricia a la oveja que se recuesta entre ambos está tomado, con algunas variantes, de un original de Rubens hoy desaparecido y expuesto en su momento en el Palacio Balbi de Génova, fechable en torno a $1628^{23}$, del que se conservan varias versiones adjudicadas al propio maestro o a su obrador - por ejemplo, en la Alte Pinakothek de Munich, en el castillo de Chenonceau, en la pinacoteca del Castello Sforzesco de Milán, en el Palacio Sansoucci de Potsdam, en el Palacio de Wilanów en Varsovia, en el Museo del Hermitage de San Petersburgo o el lienzo que se vendió en el Dorotheum de Viena en 2011 [fig. 3] - y que circuló ampliamente a través de los grabados que lo reprodujeron. El primero es una xilografía abierta por Christoffel Jegher hacia 1632-1636, donde se ha invertido la disposición de los protagonistas y del paisaje que los respalda. Sí se respeta la composición primigenia de las figuras tanto en la calcografía de Cornelis Galle I, fechable entre 1630 y 1650, donde el Niño Jesús aparece vestido con una túnica en vez de desnudo [fig. 4], como también en una segunda talla dulce debida a Gaspar Huberti, ya del tercer cuarto del XVII, esta última de formato vertical con la consiguiente reducción de la panorámica campestre y la adición, al pie de los

22 Morales, 1981: 51

23 Jaffé, 1989: 306. 


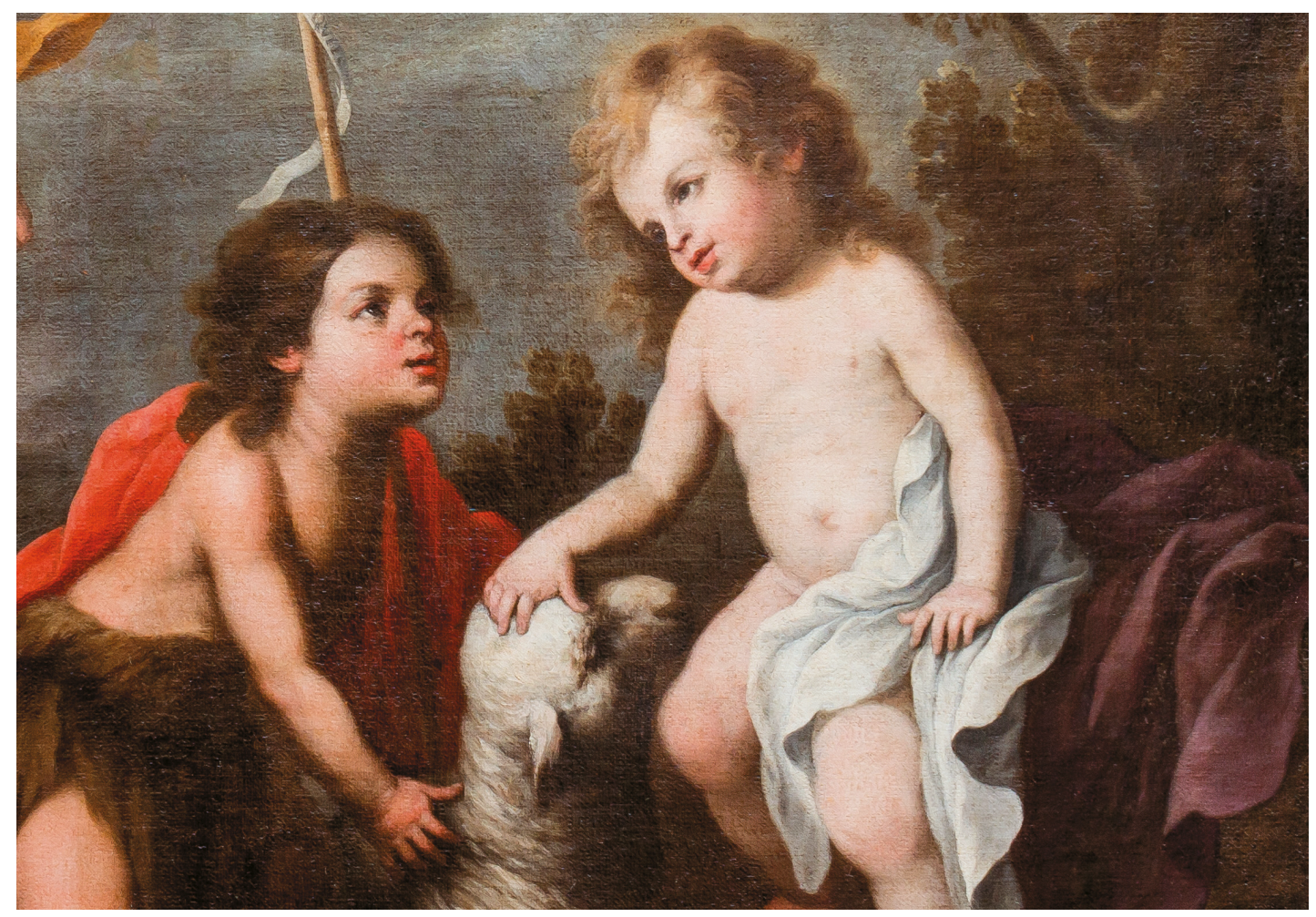

Fig. 6. Francisco Pérez de Pineda. Niño Jesús y San Juanito con el cordero (detalle). 1693.

Hermandad del Silencio, Sevilla. Foto: Jesús Romero Rodríguez.

infantes, del característico atributo del Bautista: la cruz con la filacteria del Ecce Agnus Dei, tendida sobre un peñasco [fig. 5].

Es indudable que Francisco Pérez de Pineda - como anteriormente lo había hecho Murillo en los Niños de la concha (Museo del Prado) y en el Santo Tomás de Villanueva niño repartiendo su ropa (Museo de Cincinnati) respecto a los mencionados grabados de Jegher y Galle- manejó estas estampaciones a la hora de componer en 1693 su lienzo para la desaparecida iglesia de San Miguel de Sevilla, ahora en San Antonio $\mathrm{Abad}^{24}$, bien es cierto que introduciendo una serie de transformaciones muy apreciables. La pintura de Pérez de Pineda prolonga las proporciones apaisadas del cuadro de Rubens para situar, próximo al ángulo superior izquierdo, un compacto grupo de tres ángeles niños, uno de los cuales apoya sus brazos sobre una nube, a manera de reclinatorio, con la manos unidas en actitud adoracional - en gesto que recuerda al de uno de los angelitos de los Niños de la concha de Murillo-, mientras sus dos compañeros se disponen a seguir arrojando rosas desde el cielo que, junto a otras especies florales, ya salpican el terreno donde se produce el imaginario encuentro entre el pequeño Jesús y su primo San Juanito, quienes parecen sostener un entrañable diálogo. Bañado por una suave luz crepuscular, el paisaje, que aparenta ser la ladera de una colina, apenas se ve surcado por un tronco y algunas copas de árboles; resulta, pues, menos ameno y variopinto que el radiante modelo rubeniano, conformando junto a los personajes una línea diagonal descendente desde la derecha a nuestra izquierda.

Otras diferencias respecto a la composición original de Rubens y sus reproducciones grabadas se centran en las figuras del Niño Jesús y San Juanito, aunque ciertamente sean émulas de aquellas respecto a sus posturas corporales [fig. 6]. Al Precursor, Pérez de Pineda lo ha

\footnotetext{
24 Navarrete, 1998: 198-199.
} 
cubierto, amén de la tradicional piel de camello que ciñe sus caderas, con un movido manto de intensa tonalidad encarnada, haciendo reposar en su hombro izquierdo la cruz de palo con la filacteria del Agnus Dei, que solo aparecía en la tardía estampa de Gaspar Huberti, tumbada sobre una roca. En cuanto al Niño Jesús, Pérez de Pineda lo dota de una larga y rubia cabellera, aumentando el volumen del paño blanco que oculta sus partes pudendas; pero lo más interesante es que, con evidente intención simbólica, ha trocado en morado el color rojo con que Rubens pintó la prenda, probablemente su túnica, que cubre el escaño - un tronco arbóreo en el caso de las versiones rubenianas - del que está incorporándose el divino párvulo. Es bien sabido que el morado, en la iconografía cristiana, es símbolo de realeza y de penitencia, utilizándose en los tiempos litúrgicos de Adviento y Cuaresma. En esta pintura, independientemente de la delicadeza intimista y amable que en ella puede apreciarse, y del coloquio en apariencia despreocupado de los niños, la presencia de esta túnica púrpura, del cordero cuya cabeza acaricia el Mesías e incluso de las rosas con sus espinas esparcidas por los ángeles, pueden considerarse reveladores signos premonitorios de la futura pasión de Cristo, quien desde su infancia asume su muerte sacrificial.

Con esta nueva aportación al todavía reducidísimo catálogo de Francisco Pérez de Pineda esperamos haber contribuido a que en el futuro sus obras, como declaraba Ceán, vayan dejando de estar "confundidas en su patria con las de otros pintores que siguieron como él el gusto y colorido de Murillo"25.

\section{BIBLIOGRAFÍA}

Angulo Íñiguez, Diego (1981): Murillo. Su vida, su arte su obra. Vol. II. Madrid: Espasa-Calpe.

Cañizares Japón, Ramón (2019): "La Hermandad de las Ánimas de la parroquia de San Lorenzo de Sevilla". En: Roda Peña, José (Dir.): XX Simposio sobre Hermandades de Sevilla y su provincia. Sevilla: Fundación Cruzcampo, pp. 75-106.

Ceán Bermúdez, Juan Agustín (1800): Diccionario histórico de los más ilustres profesores de las Bellas Artes en España. Vol. IV. Madrid: Imprenta de la Viuda de Ibarra.

Delgado Aboza, Francisco Manuel (2010): "La capilla sacramental de la parroquia de San Lorenzo de Sevilla". En: Roda Peña, José (Dir.): XI Simposio sobre Hermandades de Sevilla y su provincia. Sevilla: Fundación Cruzcampo, pp. 113-148.

García Baeza, Antonio (2014): Entre el obrador y la academia. La enseñanza de las artes en Sevilla durante la segunda mitad del Seiscientos. Sevilla: Ayuntamiento de Sevilla, Instituto de la Cultura y las Artes de Sevilla (ICAS).

García de la Concha Delgado, Federico (1987): Estudio histórico-institucional de la Primitiva Hermandad de los Nazarenos de Sevilla (vulgo «El Silencio»). Sevilla: Caja de Ahorros Provincial San Fernando de Sevilla.

González de León, Félix (1844): Noticia artística, histórica y curiosa de todos los edificios públicos, sagrados y profanos de esta Muy Noble, Muy Leal, Muy Heroica e Invicta Ciudad de Sevilla, y de muchas casas particulares. Sevilla: Imprenta de José Hidalgo.

Kinkead, Duncan T. (1979): "Nuevos datos sobre los pintores don Sebastián de Llanos y Valdés e Ignacio de Iriarte". En: Archivo Hispalense, 62, 191, Sevilla, pp. 191-214.

Kinkead, Duncan T. (2007): Pintores y doradores en Sevilla 1650-1699. Documentos. Bloomington: AuthorHouse.

Hernández González, Salvador (2009): "En torno a un documento para la Historia del Arte en Zafra: una escultura de San Francisco de Asís del imaginero Francisco Antonio Ruiz Gijón”. En: Zafra y su Feria, Zafra, pp. 57-59.

Jaffé, Michael (1989): Rubens. Catálogo completo. Milano: Rizzoli.

Morales, Alfredo J. (1981): La iglesia de San Lorenzo de Sevilla. Sevilla: El autor.

Navarrete Prieto, Benito (1998): La pintura andaluza del siglo XVII y sus fuentes grabadas. Madrid: Fundación de Apoyo a la Historia del Arte Hispánico.

Pastor Torres, Álvaro (2018): "Niño Jesús y San Juanito". En: Cañizares Japón, Ramón (ed.): Soledad 150 años de San Miguel a San Lorenzo. Sevilla: Hermandad Sacramental de la Soledad, 2018, p. 113.

Pérez Sánchez, Alfonso Emilio (1992): Pintura Barroca en España, 1600-1750. Madrid: Cátedra.

Quiles García, Fernando (1990): Noticias de Pintura (1700-1720). Sevilla: Ediciones Guadalquivir.

Quiles García, Fernando/ Cano Rivero, Ignacio (2006): Bernardo Lorente Germán y la pintura sevillana de su tiempo (1680-1759). Madrid: Fernando Villaverde Ediciones.

25 Ceán, 1800: 80. 
Sánchez López, Andrés (2008): La pintura de bodegones y floreros en España en el siglo XVIII. Madrid: Fundación Arte Hispánico.

Sancho Corbacho, Heliodoro (1934): Arquitectura sevillana del siglo XVIII. Sevilla: Laboratorio de Arte.

Tassara y González, José María (1919): Apuntes para la historia de la revolución de septiembre del año de 1868, en la ciudad de Sevilla. Sevilla: Oficina Tipográfica Gironés.

Valdivieso, Enrique (2003): Pintura Barroca Sevillana. Sevilla: Ediciones Guadalquivir.

Fecha de recepción: 28-II-2019

Fecha de aceptación: 17-V-2019 